\title{
Sensitivity analysis for effects of displacement amplitude and loading frequency on low-cycle fatigue lifetime in carbon/epoxy laminated composites
}

\author{
Mohammad Azadi ${ }^{1, *}$, Mohsen Alizadeh ${ }^{2}$, and Hassan Sayar ${ }^{1}$ \\ ${ }^{1}$ Faculty of Mechanical Engineering, Semnan University, Semnan, Iran \\ ${ }^{2}$ Faculty of Aerospace Engineering, Semnan University, Semnan, Iran
}

\begin{abstract}
In the present article, the low-cycle fatigue lifetime of carbon/epoxy laminated composites has been investigated. The sensitivity analysis has been also performed to study effects of the displacement amplitude and the loading frequency on the low-cycle fatigue lifetimes in composites. For such objective, displacement-control low-cycle fatigue testing has been done on the open-hole standard specimen. Fatigue tests included 4 different displacement amplitudes at $200 \mathrm{~mm} / \mathrm{min}$ of the loading frequency and 4 different loading frequencies under $7 \mathrm{~mm}$ of the displacement amplitude. The sensitivity analysis was carried out by the MINITAB software, considering a linear function for fitting experimental data by the predicting model. Experimental results showed that by increasing the displacement amplitude, the low-cycle fatigue lifetime decreased, as expected. In addition, when the loading frequency enhanced, the low-cycle fatigue lifetime of composites decreased. Besides, the maximum stress had a reverse behavior, compared to the fatigue lifetime. The sensitivity analysis depicted that the displacement amplitude was sensitive on both the fatigue lifetime and the maximum stress. The loading frequency was sensitive on the maximum stress and was not sensitive on the fatigue lifetime.
\end{abstract}

\section{Introduction}

Nowadays, composite structures have been widely in the aerospace industry. Such components are exposed to cyclic loadings, which lead to the fatigue fracture. Therefore, to know the fatigue behavior of composites is essential for engineers to design an appropriate structure, based on boundary conditions.

In this field of study, including the fatigue behavior of laminated polymer matrix composites (PMC), different researches have been presented until now, which details can be found in the literature. De Baere et al. [1] studied on the tension-tension fatigue behavior of a carbon reinforced thermoplastic to evaluate a dumbbell-shaped specimen. They depicted that there was only a small influence of the frequency on the fatigue lifetime for higher stress levels, whereas for stress levels lower than $675 \mathrm{MPa}$, a lower frequency yielded a larger number of cycles to failure. Broughton et al. [2] investigated the open-hole tension-tension fatigue behavior of a glass fiber-reinforced polymer (GFRP) laminated composite. Constant amplitude tests were conducted at two different R-ratios and the block amplitude tests involved two or more stress levels. They noted that decreasing the test frequency to $1 \mathrm{~Hz}$ reduced the surface temperature of the specimen, considerably. This reduction in temperature was accompanied by a significant reduction in the fatigue lifetime.
Yudhanto et al. [3] evaluated open-hole fatigue characteristics and the damage growth of stitched plain weave carbon/epoxy laminates. They found that the round stitch reduced the fatigue limit of carbon/epoxy plain weave laminates under tension-tension fatigue loading. Besides, the parallel stitch had no effect on the S-N curve of carbon/epoxy laminates. De Baere et al. [4] have a research on the interlaminar behavior of a carbon fabric reinforced thermoplastic lap shear specimen under quasistatic and tension-tension fatigue loading. They showed that no crack growth was visible during quasi-static experiments, except near the lifetime end, whereas significant crack growth was present during fatigue experiments. Besides, they considered two loading frequencies and observed no significant influence on the behavior and the fatigue lifetime.

Brunbauer et al. [5] checked the dependency of the fiber volume content on mechanical properties, the fatigue damage and the microstructure of carbon/epoxy laminates. They depicted that the damage behavior of offaxis specimens under tension-tension fatigue testing changed with increasing the fiber volume content and the applied cyclic load. While matrix cracking and interfacial debonding were dominating damage mechanisms in specimens with low fiber content, fiber bridging and pullout were monitored with increasing fiber content. Dai et al. [6] characterized the open-hole quasi-static and fatigue behavior of 3D woven carbon/epoxy composites. The

\footnotetext{
* Corresponding author: m_azadi@semnan.ac.ir
} 
surface crack initiation and progression during tensiontension fatigue loading was identified using thermoelastic stress analysis, which revealed that the orthogonal weave had larger surface damage area than the angleinterlock weave.

Ma et al. [7] presented the off-axis tensile fatigue assessment based on residual strength for the carbon fiberreinforced composite, at room temperature. They conducted tension-tension cyclic fatigue tests under load controlling at a sinusoidal frequency of $10 \mathrm{~Hz}$ to obtain the stress-fracture cycles (S-N) relationship. They showed that the more flexible matrix and the weaken fiber-matrix interface after the fatigue phenomenon were responsible for the modulus decrease and the strain increase. Meanwhile, no acute interfacial/matrix damage in resins during fatigue was responsible for the sustaining strength. Feng et al. [8] studied on tension-tension fatigue performances and the reliability in the fatigue lifetime of T700/MTM46 laminated composites. They indicated that failure modes of fatigue specimens were quite different with that of static specimens. The delamination phenomenon tended to be the main failure mode for fatigue specimens, while the brittle facture was dominated for static specimens.

Fujimoto et al. [9] investigated the low-cycle fatigue behaviour of carbon fiber reinforced plastic (CFRP) laminated composites under repeated out-of-plane loading. They found that the fatigue fracture occurred in a brittle manner with almost no prior deformation. Based on the fracture surface observation, the fracture at the carbon fiber/epoxy layer was predominant. Horrmann et al. [10] studied the effect of the fiber waviness on the fatigue lifetime of carbon fiber-reinforced polymer (CFRP) materials, under axial loadings. They showed that there had a severe influence on the static strength and on the fatigue lifetime of specimens.

Korkiakoski et al. [11] checked the influence of the specimen type and the reinforcement on the tensiontension fatigue lifetime of unidirectional glass fiberreinforced plastic (GFRP) laminates. Their results depicted that the test specimen type had a significant effect on the failure mode and the fatigue lifetime. Besides, a significantly higher fatigue lifetime was measured for the composite with the powder-bound fabric reinforcement, when compared to the composite with the stitched reinforcement. Cole et al. [12] found the interphase mechanical behavior of carbon fiberreinforced polymer under cyclic loading, by presenting a micro-/nano-scale technique to characterize the damage formation. They utilized a finite element model to determine a material compliance effect in fibers, which provided a basis for linking local interphase mechanical behavior to the global fatigue behavior of composites. Shen et al. [13] had an experimental investigation on the damage evaluation in cross-ply glass fiber-reinforced plastic (GFRP) laminates, subjected to quasi-static and fatigue loadings. They illustrated that fatigue loading with lower stress level accelerated the damage process and generated damages more thoroughly at failures.

Although some researches have been presented based on the frequency effect on the fatigue lifetime of composites, but still requires to investigate. Therefore, as a novel research, effects of the displacement amplitude and the loading frequency have been represented on the low-cycle fatigue lifetime in carbon/epoxy laminated polymer matrix composites. For such objective, the sensitivity analysis on experimental data was carried out by the MINITAB software. Then, obtained results have been reported in figures and tables.

\section{Materials and Experiments}

\subsection{Laminated Composite}

Standard Specimens were made of unidirectional carbon fibers (Sika-Wrap-230C) and the CR-80 epoxy (including the $\mathrm{CH}-80-2$ hardener, with the weight percent of $30 \%$ ). The thickness of each unidirectional fabric was $0.13 \mathrm{~mm}$ and 14 (or 7 symmetric) layers have been utilized for each composite plate $(250 \mathrm{~mm} \times 350 \mathrm{~mm})$. The total thickness of each laminate was $3.2 \mathrm{~mm}$, which was manufactured by the hand lay-up method. Composite layers were considered as $\left[0_{3} / 90_{2} / 0_{2}\right]_{\mathrm{s}}$, including 14 layers, as mentioned.

Then, based on the ASTM-D5766 standard [14], openhole specimens have been cut by water-jetting from the initial composite plate. The dimension of each standard specimen was $36 \mathrm{~mm} \times 250 \mathrm{~mm} \times 3.2 \mathrm{~mm}$, with the hole diameter of $6 \mathrm{~mm}$. The standard specimen geometry can be seen in Fig. 1.

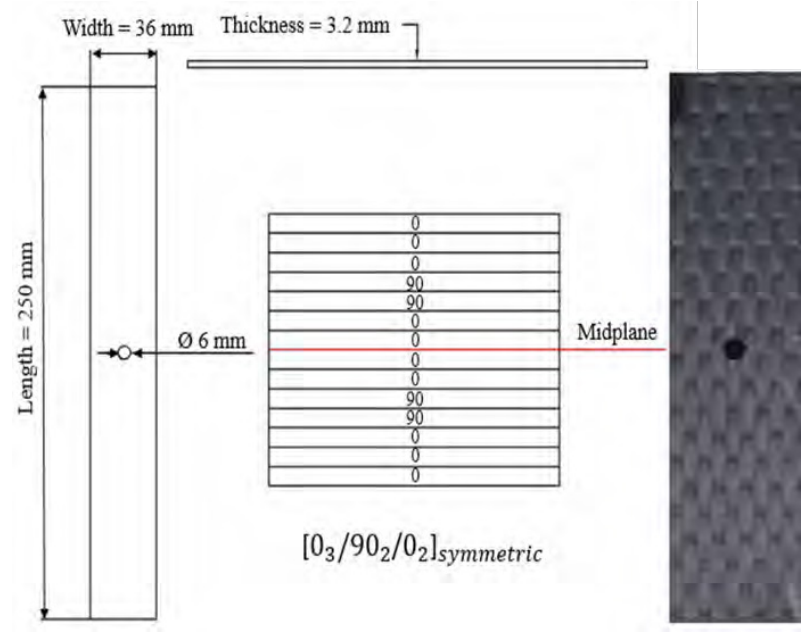

Fig. 1. The geometry of the standard specimen.

\subsection{Fatigue Testing}

For fatigue testing, a universal tension-compression device, STM-150 Santam Company, was utilized with the loading capacity of 15 tons. Fig. 2 shows the equipment of fatigue testing. Cyclic loadings were applied on standard specimens under a tension-tension condition. Fatigue tests were displacement-controlled and the displacement ratio $\left(R_{d}=d_{\min } / d_{\max }\right)$ was zero, means that the minimum displacement was zero. Two parameters were considered to change for low-cycle fatigue test conditions, including the displacement amplitude and the loading frequency. When the loading frequency was 200 
$\mathrm{mm} / \mathrm{min}$, the displacement amplitude was 5.5, 6.0, 6.5 and $7.0 \mathrm{~mm}$. When the displacement amplitude was $7.0 \mathrm{~mm}$, the loading frequency was $25,50,100$ and $200 \mathrm{~mm} / \mathrm{min}$.

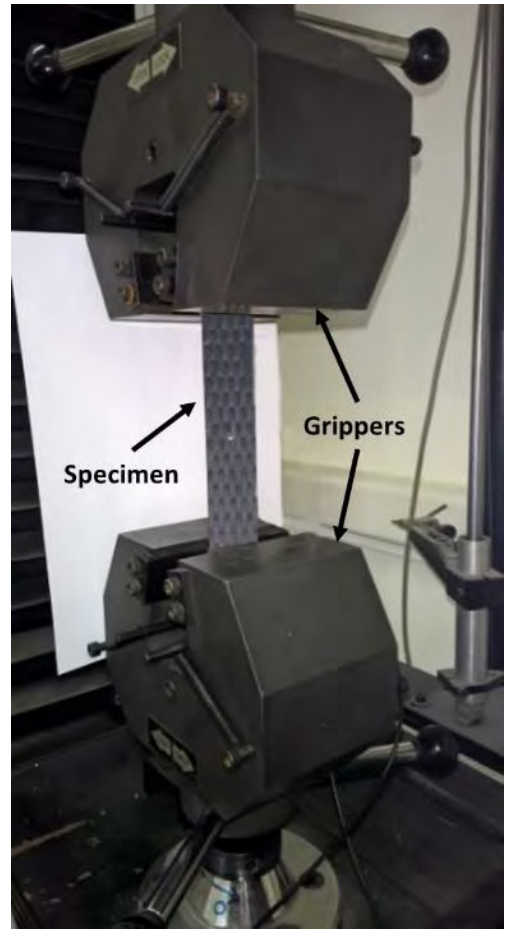

Fig. 2. The equipment of fatigue testing.

The scanning electron microscopy, XL30 Philips Company, was also used to investigate the fracture surface of specimens. Before, each specimen was coated by silver under a vacuum environment, since the composite was not conductive.

\subsection{Regression Analysis}

Generally in the statistical analysis, the F-value and the Pvalue can be used for finding the effectiveness of parameters. The F-value is the ratio of residual variances in a model, without the predictor versus with the predictor. Values closed to unity show that the predictor does not affect the residual variance. Large values indicates a reduction in the residual variance that can be attributed to the predictor. However, the P-value shows that the predictor is uncorrelated to the response [15].

Before using a model (or a formulation) for the objective function based on factors, the sensitivity analysis should be carried out based on statistical data. For this objective, the effectiveness of each parameter (or factor or predictor) could be calculated by comparing $F_{0}$ to $F_{\alpha, a-1, N-a}$. It should be noted that $a-1$ and $N-a$ are the degree of freedom of the treatment and the error, respectively [15]. Besides, $\alpha$ is the risk value, which was considered as 0.05 , based on $95 \%$ of the confidence level.

The value of $F_{0}$ can be calculated based on mean squared values $(M S)$ of treatments (including factor levels) and the error [15-16].

$$
F_{0}=M S_{\text {treatment }} / M S_{\text {error }}
$$

Then also, $F_{\alpha, a-1, N-a}$ can be found from the analysis of variance (ANOVA tables) [15]. The condition of the effectiveness of factors can be written as follows,

$$
F_{0}>F_{\alpha, a-1, N-a}
$$

As mentioned, the F-value is based on the ratio of mean squares. The F-value is used to test the overall significance for a regression model, to compare fits of different models, to test specific regression terms, and to test the equality of means [15].

Another parameter, which is the P-Value, could be considered for finding the effectiveness of factors. The Pvalue can be utilized to determine the statistical significance, in a hypothesis test. One factor would be effective, when the P-Value is lower than 0.05 [15-16]. All these calculations was performed in the MINITAB software. The fitted model for the objective function, $N_{f}$ (the low-cycle fatigue lifetime) and $S_{\max }$ (the maximum stress) were considered as follows,

$$
\begin{gathered}
N_{f}=C_{0}+C_{1} \times(\text { dor } f) \\
S_{\text {max }}=D_{0}+D_{1} \times(\text { d or } f)
\end{gathered}
$$

Where $d$ and $f$ were the displacement amplitude and the loading frequency, respectively. Besides, $C_{0}, C_{l}, D_{0}$ and $D_{l}$ were statistical constants, which could be calculated from the regression analysis. It should be noted that the regression analysis is to find a mathematical relationship between variables. Ideally in the regression analysis, one tries to keep changes in factors, independent of each other [15].

To check the accuracy of predicted models, besides relative errors between calculated and experimental data, the coefficient of determination $\left(R^{2}\right)$ could be used. It should be noted that the adjusted $R^{2}$ value is to determine how well the model fits data, when the number of predictors in the model is adjusted. The adjusted $R^{2}$ value incorporates the number of predictors in the model to help to choose the correct model. In addition, the predicted $R^{2}$ value is to determine how well the model predicts responses for new observations. Larger values of the predicted $R^{2}$ value indicate models in a greater predictive ability. Since the predicted $R^{2}$ value is calculated by systematically removing each observation from the data set, estimating the regression equation, and determining how well the model predicts the removed observation [15].

\section{Results and Discussions}

Obtained results including the stress history versus the low-cycle fatigue lifetime can be seen in Figs. 3 to 6 . In these figures, the stress history included the maximum stress, the minimum stress, the stress amplitude and the mean stress, all versus the low-cycle fatigue lifetime. As a result, by increasing the loading frequency, the stress increased and the fatigue lifetime decreased, under a constant displacement amplitude. In addition, when the displacement amplitude decreased, the stress also decreased and therefore, the fatigue lifetime increased, under a constant loading frequency, as expected. 
Effects of the displacement amplitude and the loading frequency on the low-cycle fatigue lifetime and the maximum stress of carbon/epoxy composites can be seen in Figs. 7 and 8.

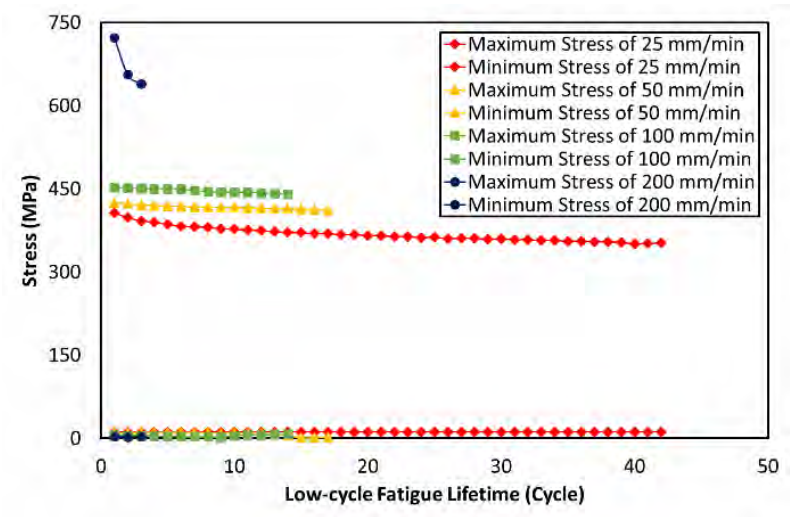

Fig. 3. The stress history (the maximum stress and the minimum stress) versus the low-cycle fatigue lifetime, under the displacement amplitude of $7 \mathrm{~mm}$.

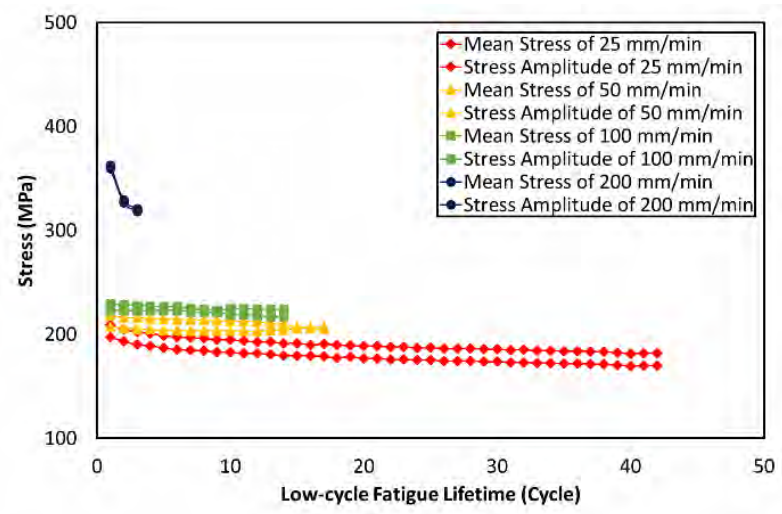

Fig. 4. The stress history (the mean stress and the stress amplitude) versus the low-cycle fatigue lifetime, under the displacement amplitude of $7 \mathrm{~mm}$.

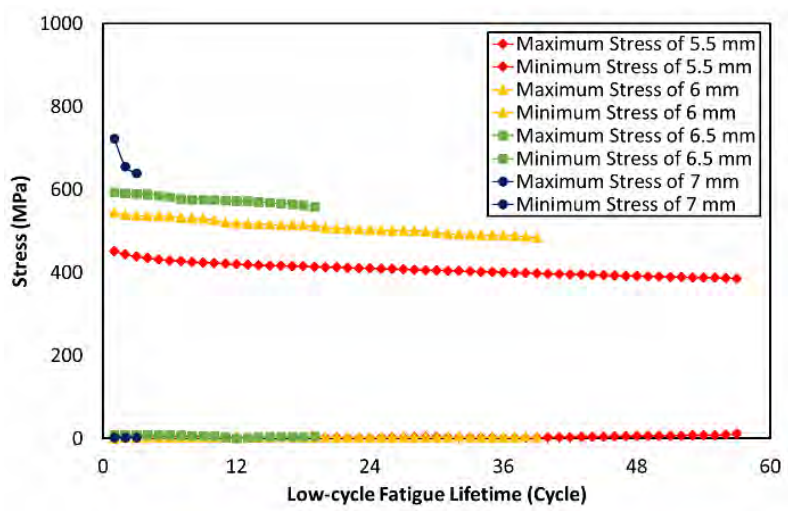

Fig. 5. The stress history (the maximum stress and the minimum stress) versus the low-cycle fatigue lifetime, under the loading frequency of $200 \mathrm{~mm} / \mathrm{min}$.

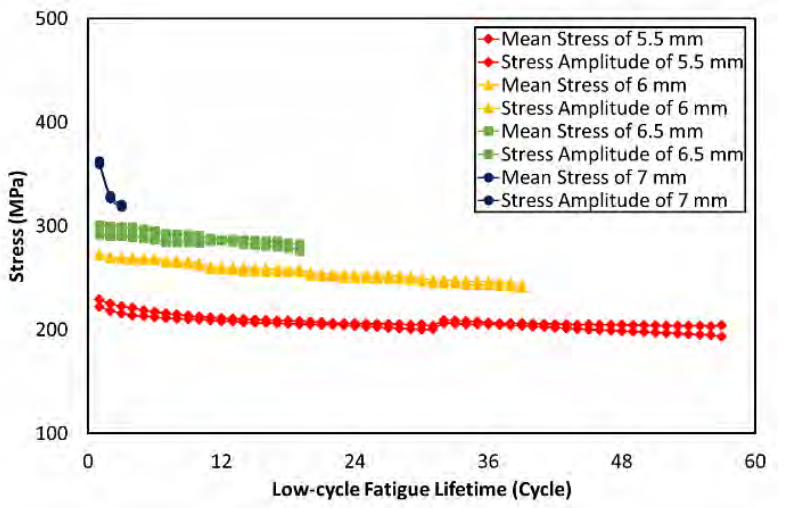

Fig. 6. The stress history (the mean stress and the stress amplitude) versus the low-cycle fatigue lifetime, under the loading frequency of $200 \mathrm{~mm} / \mathrm{min}$.

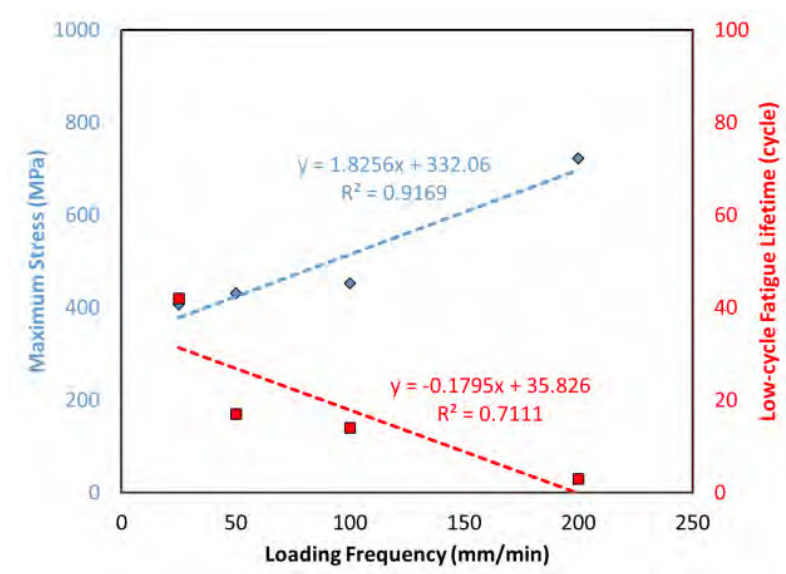

Fig. 7. The effect of the loading frequency on the maximum stress and the low-cycle fatigue lifetime, under the displacement amplitude of $7 \mathrm{~mm}$.

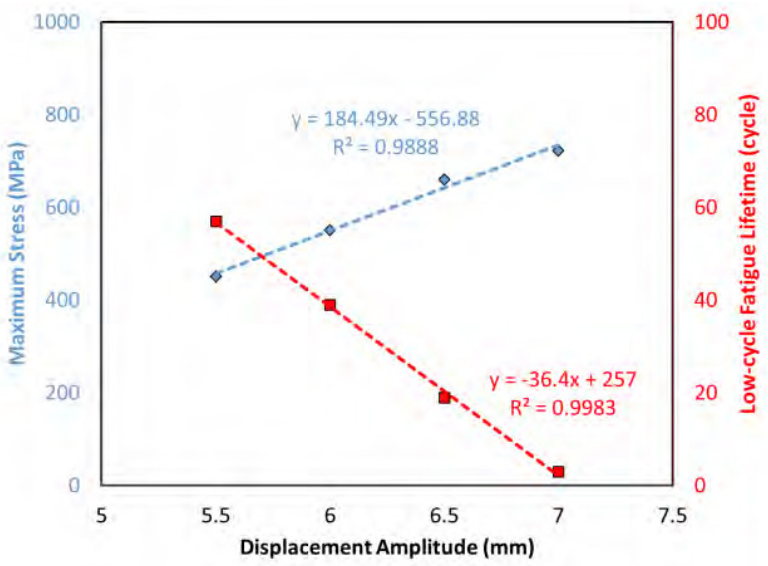

Fig. 8. The effect of the displacement amplitude on the maximum stress and the low-cycle fatigue lifetime, under the loading frequency of $200 \mathrm{~mm} / \mathrm{min}$.

According to Figs. 7 and $8, R^{2}$ values for linear curve fitting were more than $92 \%$, unless one condition, including the fatigue lifetime versus the loading frequency, which was about $71 \%$, as a proper value. 
Based on obtained results from the regression analysis, Tables 1 to 4 present F-value, P-value and coefficients of determination $\left(R^{2}\right)$, for effects of the displacement amplitude and the loading frequency on the fatigue lifetime and the maximum stress. As mentioned in the previous part, the P-value should be less than 0.05 [15-16] to consider a factor as an effective or sensitive parameter. Based on the objective, the fatigue lifetime and the maximum stress, the displacement amplitude was an effective parameter. Since the P-value was obtained as 0.001 and 0.006 , respectively. However, based on the fatigue lifetime as an objective, the P-value was not proper and more than 0.05 . This means that the loading frequency was not effective. When the objective was the maximum stress, the loading frequency was effective, since the P-value was 0.042 , less than 0.05 . It should be noted that $R^{2}$ values in Tables 1 to 4 were the same as $R^{2}$ values in Figs. 7 and 8. As the last result, adjusted and predicted $R^{2}$ values were proper for the regression analysis of the relation between the fatigue lifetime or the maximum stress and the displacement amplitude. However, these results were not proper for the regression analysis of the relation between the fatigue lifetime or the maximum stress and the loading frequency.

Table 1. The regression analysis for the displacement amplitude effect on the fatigue lifetime.

\begin{tabular}{|c|c|c|c|c|c|}
\hline & DF & $\begin{array}{c}\text { Adj. } \\
S S\end{array}$ & $\begin{array}{c}\text { Adj. } \\
M S\end{array}$ & $\begin{array}{c}\text { F- } \\
\text { Value }\end{array}$ & $\begin{array}{c}\text { P- } \\
\text { Value }\end{array}$ \\
\hline Regression & 1 & 1656.2 & 1656.2 & 1183.0 & 0.001 \\
\hline Displacement & 1 & 1656.2 & 1656.2 & 1183.0 & 0.001 \\
\hline Error & 2 & 2.8 & 1.4 & - & - \\
\hline Total & 3 & 1659.0 & $S=1.18$ & $R^{2}=99.83 \%$ \\
\hline \multicolumn{2}{|c|}{$R^{2}$ adjusted $=99.75 \%$} & \multicolumn{2}{|c|}{$R^{2}$ predicted $=99.28 \%$} \\
\hline
\end{tabular}

*DF: Degree of freedom, Adj.: Adjusted.

Table 2. The regression analysis for the displacement amplitude effect on the maximum stress.

\begin{tabular}{|c|c|c|c|c|c|}
\hline & DF & Adj. SS & $\begin{array}{c}\text { Adj. } \\
M S\end{array}$ & $\begin{array}{c}\text { F- } \\
\text { Value }\end{array}$ & $\begin{array}{c}\text { P- } \\
\text { Value }\end{array}$ \\
\hline Regression & 1 & 42544.4 & 42544.4 & 176.7 & 0.006 \\
\hline Displacement & 1 & 42544.4 & 42544.4 & 176.7 & 0.006 \\
\hline Error & 2 & 481.7 & 240.8 & - & - \\
\hline Total & 3 & 43026.1 & $S=15.52$ & $R^{2}=98.88 \%$ \\
\hline \multicolumn{2}{|c|}{$R^{2}$ adjusted } & $=98.32 \%$ & \multicolumn{2}{|c|}{$R^{2}$ predicted $=94.00 \%$} \\
\hline
\end{tabular}

*DF: Degree of freedom, Adj.: Adjusted.
Table 3. The regression analysis for the loading frequency effect on the fatigue lifetime.

\begin{tabular}{|c|c|c|c|c|c|}
\hline & DF & $\begin{array}{c}\text { Adj. } \\
S S\end{array}$ & Adj. MS & $\begin{array}{c}\text { F- } \\
\text { Value }\end{array}$ & $\begin{array}{c}\text { P- } \\
\text { Value }\end{array}$ \\
\hline Regression & 1 & 578.8 & 578.8 & 4.92 & 0.157 \\
\hline Frequency & 1 & 578.8 & 578.8 & 4.92 & 0.157 \\
\hline Error & 2 & 235.2 & 117.6 & - & - \\
\hline Total & 3 & 814.0 & $S=10.85$ & $R^{2}=71.11 \%$ \\
\hline \multicolumn{2}{|c|}{$R_{\text {adjusted }}^{2}=56.66 \%$} & \multicolumn{2}{c|}{$R^{2}$ predicted $=0.00 \%$} \\
\hline
\end{tabular}

*DF: Degree of freedom, Adj.: Adjusted.

Table 4. The regression analysis for the loading frequency effect on the maximum stress.

\begin{tabular}{|c|c|c|c|c|c|}
\hline & DF & $\begin{array}{c}\text { Adj. } \\
S S\end{array}$ & Adj. $M S$ & $\begin{array}{c}\text { F- } \\
\text { Value }\end{array}$ & $\begin{array}{c}\text { P- } \\
\text { Value }\end{array}$ \\
\hline Regression & 1 & 59884 & 59884 & 22.08 & 0.042 \\
\hline Frequency & 1 & 59884 & 59884 & 22.08 & 0.042 \\
\hline Error & 2 & 5425 & 2712 & - & - \\
\hline Total & 3 & 65309 & $S=52.08$ & $R^{2}=91.69 \%$ \\
\hline \multicolumn{2}{|c|}{$R_{\text {adjusted }}^{2}=87.54 \%$} & \multicolumn{2}{|c|}{$R^{2}$ predicted $=16.19 \%$} \\
\hline
\end{tabular}

*DF: Degree of freedom, Adj.: Adjusted.

The formulation for the fatigue lifetime $\left(N_{f}\right)$ versus the displacement amplitude $(d)$ can be written as follows,

$$
N_{f}(\text { cycle })=257.00-36.4 d(\mathrm{~mm})
$$

The formulation for the maximum stress $\left(S_{\max }\right)$ versus the displacement amplitude $(d)$ can be written as follows,

$$
S_{\max }(\mathrm{MPa})=-556.9+184.5 d(\mathrm{~mm})
$$

The formulation for the fatigue lifetime $\left(N_{f}\right)$ versus the loading frequency $(f)$ can be written as follows,

$$
N_{f}(\text { cycle })=35.83-0.1785 f(\mathrm{~mm} / \mathrm{min})
$$

The formulation for the maximum stress $\left(S_{\max }\right)$ versus the loading frequency $(f)$ can be written as follows,

$$
S_{\max }(\mathrm{MPa})=332.1+1.826 f(\mathrm{~mm} / \mathrm{min})
$$

As a discussion, Staehler et al. [17] observed the dependency of the loading frequency on the high-cycle fatigue lifetime between 40 and $375 \mathrm{~Hz}$, in carbon fiberreinforced silicon carbide composites. They showed that lower loading frequency (4 to $40 \mathrm{~Hz}$ ) had no effects on the fatigue lifetime. It means that there was no difference in cycles to failure, between 4 or $40 \mathrm{~Hz}$. 
In general, they found mechanisms, which were responsible for the reduction in the fatigue lifetime of composites, under highest loading frequency, including the macroscopic behavior (such as the stress-strain response during cycling), microscopic characteristics (failure and damage mechanisms), and also temperature effects. They indicated that one reason can be the specimen surface temperature, which increased due to the internal heat generation from the sliding friction between constituents of the composite, under cyclic loading. This enhancement was directly related to the loading frequency and/or the applied cyclic stress level. However, they showed that there was no clear indication that the loading frequency greatly impacted either the stress-strain response or the overall appearance of fracture surfaces. However, a closer examination of specimens, cycled at the highest frequency $(375 \mathrm{~Hz})$, illustrated an evidence of the localized oxidation at fiber surfaces that might have attributed to the reduction in the fatigue lifetime at this frequency [17].

Mall et al. [18] repeated such study, but for the elevated temperature of $550^{\circ} \mathrm{C}$ on the same material, carbon fiberreinforced silicon carbide composites, under the tensiontension high-cycle fatigue loading at three frequencies of $0.1,10$ and $375 \mathrm{~Hz}$.

They indicated that there was an increase in cycles to failure, as the loading frequency changed from 0.1 to 375 $\mathrm{Hz}$. This trend was different at room temperature. Their analysis of damage mechanisms illustrated that the oxidation of carbon fibers was the major difference between room and elevated temperatures. Such phenomenon caused to a reduction in cycles to failure, under lower loading frequencies at the elevated temperature, in comparison to that at room temperature. In other words, by increasing the loading frequency, because of the internal friction between fibers and the matrix, caused to an increase in the internal temperature of the composite. Matrix cracks from the mismatch between coefficients of the thermal expansion in carbon fibers and the silicon carbide matrix initiated at higher temperatures, due to higher loading frequencies [18].

\section{Conclusions}

In this article, the sensitivity analysis for effects of the displacement amplitude and the loading frequency on the low-cycle fatigue lifetime in carbon/epoxy laminated composites was conducted. Experimental obtained results can be mentioned as follows,

- By increasing the displacement amplitude, the low-cycle fatigue lifetime decreased, as expected.

- When the loading frequency enhanced, the lowcycle fatigue lifetime of composites decreased.

- The maximum stress had a reverse behavior, compared to the fatigue lifetime.
- The displacement amplitude was effective or sensitive on both the fatigue lifetime and the maximum stress.

- The loading frequency was effective or sensitive only on the maximum stress and was not effective or sensitive on the fatigue lifetime.

As an acknowledgement, authors should thank Irankhodro Powertrain Company (IPCo.), in Tehran, Iran, for the financial support on this project.

\section{References}

1. I. De Baere, W. Van Paepegem, C. Hochard, J. Degrieck, Polym. Testing 30, 663 (2011)

2. W.R. Broughton, M.R.L. Gower, M.J. Lodeiro, G.D. Pilkington, R.M. Shaw, Compos. Part A 42, 1310 (2011)

3. A. Yudhanto, Y. Iwahori, N. Watanabe, H. Hoshi, Int. J. Fatigue 43, 12 (2012)

4. I. De Baere, W. Van Peapegem, I. Degrieck, Polym. Testing 32, 1273 (2013)

5. J. Brunbauer, H. Stadler, G. Pinter, Int. J. Fatigue 70, 85 (2015)

6. S. Dai, P.R. Cunningham, S. Marshall, C. Silva, Compos. Struct. 131, 765 (2015)

7. Y. Ma, Y. Zhang, T. Sugahara, S. Jin, Y. Yang, H. Hamada, Compos. Part A 90, 711 (2016)

8. Y. Feng, C. Gao, Y. He, T. An, C. Fan, H. Zhang, Compos. Struct. 136, 64 (2016)

9. K. Fujimoto, M. Hojo, A. Fujita, Proc. Struct. Integ. 2, 182 (2016)

10. S. Horrmann, A. Adumitroaie, C. Viechtbauer, M. Schagerl, Int. J. Fatigue 90, 139 (2016)

11. S. Korkiakoski, P. Brondsted, E. Sarlin, O. Saarela, Int. J. Fatigue 85, 114 (2016)

12. D.P. Cole, T.C. Henry, F. Gardea, R.A. Haynes, Compos. Sci. Technol. 151, 202 (2017)

13. H. Shen, W. Yao, W. Qi, J. Zong, Compos. Part B 120, 10 (2017)

14. ASTM D5766, Standard test method for open-hole tensile strength of polymer matrix composite laminates (ASTM, 2011)

15. D.C. Montgoery, Design and analysis of experiments (John Wiley and Sons, 2012)

16. M. Azadi, M. Iziy, A. Marbout, M. Azadi, A. Hajiali Mohammadi, J. Engine Res. 43, 63 (2016)

17. J.M. Staehler, S. Mall, L.P. Zawada, Compos. Sci. Technol. 63, 2121 (2003)

18. S. Mall, J.M. Engesser, Compos. Sci. Technol. 66, 863 (2006) 